\title{
P-coretractable and Strongly P-coretractable Modules
}

\author{
Inaam Mohammed Ali Hadi ${ }^{1}$ and Shukur Neamah Al-aeashi ${ }^{2}$, \\ ${ }^{1}$ Department Of Mathematics, College Of Education for Pure Sciences (Ibn-Al-Haitham) \\ University Of Baghdad , Iraq \\ ${ }^{2}$ Department Of Urban Planning, College Of Physical Planning \\ University Of Kufa, Iraq \\ "Corresponding author's email: shukur.mobred [AT] uokufa.edu.iq
}

\begin{abstract}
In this paper, we introduce the notion of P-coretractable module. Some basic properties of this class of modules are investigated and some relationships between these modules and other related concepts are introduced . Also, we give the notion of strongly P-coretractable and study it comparison with P-coretractable, moreover the mono-P-coretractable concept are introduced and studied .
\end{abstract}

Keywords- (strongly) coretractable modules, (strongly) P-coretractable, mono-coretractable , mono-P-coretractable , purely-Rickart .

\section{INTRODUCTION}

Throughout this paper all rings have identities and all modules are unital right $\mathrm{R}$-modules . A module $\mathrm{M}$ is called coretractable if for each a proper submodule $N$ of $M$, there exists a nonzero R-homomorphism $f: M / N \rightarrow M[1]$, and $M$ is called strongly coretractable module if for each proper submodule $\mathrm{N}$ of $\mathrm{M}$, there exists a nonzero $\mathrm{R}$-homomorphism $\mathrm{f}: \mathrm{M} / \mathrm{N} \rightarrow \mathrm{M}$ such that $\mathrm{Imf}+\mathrm{N}=\mathrm{M}[2],[8]$. It is clear every strongly coretractable module is coretractable but it is not conversely. This work consists of three sections, in section one, we introduce the notion of purely-coretractable or Pcoretractable module where an R-module $\mathrm{M}$ is called $\mathrm{P}$-coretractable if for each proper pure submodule $\mathrm{N}$ of $\mathrm{M}$, there

exists a nonzero homomorphism $\mathrm{f} \in \mathrm{Hom}_{\mathrm{R}}(\mathrm{M} / \mathrm{N}, \mathrm{M})$ also we give some examples and remarks about it . Some basic properties of P-coretractable modules are given . In section two, we introduce the notion of mono-P-coretractable . In section three, we introduce and study the notion of strongly P-coretractable module and we compare its properties with properties of P-coretractable module .

\section{PURELY-CORETRACTABLE (BRIEFLY P-CORETRACTABLE)}

In this section, we introduce the concept of P-coretractable module and give some properties of this class module . In the beginning, we recall a submodule $\mathrm{N}$ of an $\mathrm{R}$-module $\mathrm{M}$ is a pure , if for every finitely generated ideal I of $\mathrm{R}$, $\mathrm{IM} \cap \mathrm{N}=\mathrm{IN}[3]$.

Definition(1.1): An R-module is called purely-coretractable (Briefly P-coretractable) if for each proper pure submodule $\mathrm{N}$ of $\mathrm{M}$, there exists a nonzero homomorphism $\mathrm{f} \in \mathrm{Hom}(\mathrm{M} / \mathrm{N}, \mathrm{M})$.

Equivalently, $\mathrm{M}$ is a P-coretractable module if for each proper pure submodule $\mathrm{N}$ of $\mathrm{M}$, there exists $\mathrm{g} \in \mathrm{End}_{\mathrm{R}}(\mathrm{M})$, $\mathrm{g} \neq 0$ and $\mathrm{g}(\mathrm{N})=0$. A ring $\mathrm{R}$ is called $\mathrm{P}$-coretractable if $\mathrm{R}$ is $\mathrm{P}$-coretractable $\mathrm{R}$-module .

Examples and Remark(1.2):

(1) Every coretractable module is P-coretractable . But the converse is not true in general and we shall give an example later after Corollary(1.13)

(2) Every semisimple module is $\mathrm{P}$-coretractable module but the converse is not true in general . For example, $\mathrm{M}=\mathrm{Z}_{4}$ as Z-module is not semisimple module, but $\mathrm{M}$ is $\mathrm{P}$-coretractable module since 0 is the only proper pure submodule of $\mathrm{M}$.

(3) Every pure simple R-module is a P-coretractable. Where an R-module $\mathrm{M}$ is called pure simple module if the only two pure submodules are 0 and $\mathrm{M}[4]$.

The converse of this Remark is not true in general . For example Consider $\mathrm{M}=\mathrm{Z}_{2} \oplus \mathrm{Z}_{2}$ as $\mathrm{Z}$-module is P-coretractable module but not pure simple module .

(4) Every pure split module is P-coretractable module . Where an R-module $\mathrm{M}$ is called pure split if every pure submodule is a direct summand of $M[5]$. In particular $Z_{8} Z_{2}$ is pure split, so it is $P$-coretractable . 
(5) Let $\mathrm{P}$ be the set of all prime numbers and $\mathrm{M}=\prod_{\mathrm{p} \in \mathrm{P}} \mathrm{Zp}$ (That is $\mathrm{M}=\mathrm{Z}_{2} \times \mathrm{Z}_{3} \times \mathrm{Z}_{5} \times \ldots$ ). Then we shall show that $\mathrm{M}$ is not P-coretractable module . Let $\mathrm{K}=\oplus_{\mathrm{p} \in \mathrm{P}} \mathrm{Z}_{\mathrm{p}}$, then $\mathrm{K}$ is a pure submodule of $\mathrm{M}$ by [6, Lam. 4.84(d)] . Then by using the same argument of proof of $[1, \operatorname{Example}(2.9)]$. Let $\mathrm{f} \in \mathrm{Hom}_{\mathrm{R}}\left(\mathrm{M} / \mathrm{K}, \mathrm{Z}_{\mathrm{p}}\right)$ for some $\mathrm{p} \in \mathrm{P}, \mathrm{M} / \mathrm{K}=\mathrm{PM}+\mathrm{K} / \mathrm{K}=\mathrm{P}(\mathrm{M} / \mathrm{K}) \subseteq \mathrm{kerf}$, so $\mathrm{f}=0$. Hence $\operatorname{Hom}(\mathrm{M} / \mathrm{K}, \mathrm{M}) \cong \Pi_{\mathrm{p} \in \mathrm{p}} \operatorname{Hom}\left(\frac{\mathrm{M}}{\mathrm{K}}, \mathrm{Z}_{\mathrm{p}}\right)=0$, then $\mathrm{M}$ is not P-coretractable module . However $\mathrm{Z}_{\mathrm{p}}$ (for any $\mathrm{p}$ $\in \mathrm{P})$ is $\mathrm{P}$-coretractable module .

(6) Let $\mathrm{M} \cong \mathrm{M}^{\prime}$ where $\mathrm{M}$ is a $\mathrm{P}$-coretractable $\mathrm{R}$-module. Then $\mathrm{M}^{\prime}$ is a P-coretractable R-module

Proof : we shall introduce the proof in section three by more generally. See Proposition(3.3) .

(7) P-coretractability is not preserved by taking submodules, factor modules and direct summands since for any Rmodule $\mathrm{M}$ and a cogenerator R-module $\mathrm{C}, \mathrm{C} \oplus \mathrm{M}$ is a cogenerator and so is a coretractable module and so $\mathrm{P}$ coretractable, but $\mathrm{M}$ need not be coretractable module .

(8) Let $\mathrm{R}$ be a PID , M is an R-module . If M is C-coretractable, then M is P-coretractable . Where an R-module M is called $\mathrm{C}$-coretractable module if for each proper closed submodule $\mathrm{N}$ of $\mathrm{M}$, there exists a nonzero homomorphism $\mathrm{f} \in \mathrm{Hom}_{\mathrm{R}}(\mathrm{M} / \mathrm{N}, \mathrm{M})$. A ring $\mathrm{R}$ is called C-cortractable if $\mathrm{R}$ is $\mathrm{C}$ - cortractable R-module [8] .

Proof: Let N be a proper pure submodule of M . By [6,Lam, Exc.15,P.242], N is closed . As M is C-coretractable , then there exists $f \in \operatorname{End}_{R}(M), f \neq 0$ and $f(N)=0$. Thus $M$ is P-coretractable .

(9) Let $\mathrm{R}$ be a PID , $\mathrm{M}$ is an R-module. If $\mathrm{M}$ is coquasi-Dedkend, then $\mathrm{M}$ is P-coretractable . Where an R-module $M$ is coquasi-Dedekind module if for each $f \in \operatorname{End}_{R}(M), f \neq 0, f$ is an epimomorphism . [7, Theorem(2.1.4) ,P.33] .

Proof: By [7,Theorem(2.1.15)] , M has no proper nonzero pure submodule, that is $\mathrm{M}$ is pure simple . Thus $\mathrm{M}$ is $\mathrm{P}$ coretractable by part (3)

(10) Let $\mathrm{M}=Z_{P^{\infty 0}}$ as $\mathrm{Z}$-module is $\mathrm{P}$-coretractable and injective . Then $\mathrm{M}=\oplus_{i \in I} \mathrm{M}_{\mathrm{i}}\left(\mathrm{M}_{\mathrm{i}}=\mathrm{M}\right)$ is $\mathrm{P}$-coretractable since $\mathrm{M}$ is C-coretractable by Example (2) after Theorem(1.10) ) in [8], and Z is a PID . But M is not coquasi-Dedekind .

Recall that an R-module $\mathrm{M}$ is called purely extending if every submodule is essential in pure submodule Equivalently, $\mathrm{M}$ is purely extending if and only if every closed submodule is pure in $\mathrm{M}$ [9] .

Proposition(1.3): Let $\mathrm{M}$ be a purely extending R-module, if $\mathrm{M}$ is a P-coretractable, then $\mathrm{M}$ is a $\mathrm{C}$-coretractable module .

Proof: Let $\mathrm{K}$ be a proper closed submodule of $\mathrm{M}$. Since $\mathrm{M}$ is a purely extending module, then $\mathrm{K}$ is pure submodule . But $M$ is a P-coretractable module, so there exists $f \in \operatorname{End}_{R}(M), f \neq 0 f(K)=0$, then $M$ is a C-coretractable module .

Recall that an R-module $\mathrm{M}$ is said to be regular (or F-regular) if $\mathrm{R} / \mathrm{ann}(\mathrm{x})$ is regular ring for all nonzero $\mathrm{x} \in \mathrm{M}$ [10,P.29] .

Equivalently, an R-module $\mathrm{M}$ is said to be regular (F-regular) if every submodule of $\mathrm{M}$ is a pure submodule [10,Theorem (1.7), P.35] .

Corollary(1.4): Let M be an F-regular R-module, then if M is a P-coretractable module, then $\mathrm{M}$ is a C-coretractable module .

Proof: It is clear since every F-regular is purely extending module and hence by Proposition(1.3) the result holds .

Proposition(1.5): Let M be an F-regular R-module, then M is a coretractable if and only if M is a $\mathrm{P}$-coretractable .

Proof : $(\Rightarrow)$ It is clear.

$(\Leftarrow)$ Let $\mathrm{N}$ be a proper submodule of $\mathrm{M}$. Since $\mathrm{M}$ is F-regular module, so $\mathrm{N}$ is pure submodule . But $\mathrm{M}$ is $\mathrm{P}$ coretractable module, hence there exists $f \in \operatorname{End}_{R}(M), f \neq 0$ and $f(N)=0$, then $M$ is coretractable module .

Recall that an R-module $\mathrm{M}$ is called a purely lifting if for every submodule $\mathrm{N}$ of $\mathrm{M}$, there exists a pure submodule $\mathrm{K}$ of $\mathrm{M}$ such that $\mathrm{K} \subseteq \mathrm{N}$ and $\mathrm{N} / \mathrm{K}$ is small in $\mathrm{M} / \mathrm{K}$ [11]. An R-module $\mathrm{M}$ is called a $\mathrm{V}$-module if for every factor module $\mathrm{N}$ of $\mathrm{M}, \operatorname{Rad}(\mathrm{N})=0[12]$.

Corollary(1.6): If $\mathrm{M}$ is a purely lifting V-module. Then $\mathrm{M}$ is a P-coretractable if and only if $\mathrm{M}$ is a coretractable module .

Proof : Since M is V-module and M is purely lifting. Then M is an F-regular module [11,Proposition(2.2.4),P.40]. Hence we get the results by Proposition(1.5) .

Recall that an R-module $\mathrm{M}$ is called quasi-Dedekind if every proper nonzero submodule $\mathrm{N}$ of $\mathrm{M}$ is quasi-invertible where a submodule $\mathrm{N}$ of $\mathrm{M}$ is called quasi-invertible if $\mathrm{Hom}_{R}(\mathrm{M} / \mathrm{N}, \mathrm{M})=0$ [13] . A nonzero ideal ( right ideal) I of a ring $\mathrm{R}$ is quasi-invertable ideal (right ideal) of $\mathrm{R}$ if $\mathrm{I}$ is quasi-invertable submodule of $\mathrm{R}$. Also $\mathrm{M}$ is a quasi-Dedekind $\mathrm{R}$ module if for any nonzero $f \in \operatorname{End}_{R}(M), f$ is monomorphism ; that is $\operatorname{kerf}=(0)[13, \operatorname{Theorem}(1.5), P .26]$.

Proposition(1.7): Let M be a P-coretractable quasi-Dedekind R-module. Then $\mathrm{M}$ is a pure simple .

Proof : Let $\mathrm{N}$ be a proper pure submodule of $\mathrm{M}$. Then there exists $\mathrm{f} \in \operatorname{End}_{\mathrm{R}}(\mathrm{M}), \mathrm{f} \neq 0$ and $\mathrm{f}(\mathrm{N})=0$. As $\mathrm{M}$ is quasi-Dedekind module, hence $\mathrm{f}$ is monomorphism. Thus $\mathrm{N}=0$ and hence $\mathrm{M}$ is pure simple module.

Recall that an R-module $M$ is called purely Rickart if for all $f \in \operatorname{End}_{R}(M)$, kerf is pure submodule of $M$ [14] . 
Theorem(1.8): Let $\mathrm{M}$ be a purely Rickart R-module. Then $\mathrm{M}$ is coretractable module if and only if for all proper submodule $\mathrm{K}$ of $\mathrm{M}$, there exists a pure submodule $\mathrm{W}$ of $\mathrm{M}$ such that $\mathrm{K} \subseteq \mathrm{W}$ and $\mathrm{M}$ is $\mathrm{P}$-coretractable.

Proof : $(\Rightarrow)$ Clear that $\mathrm{M}$ is $\mathrm{P}$-coretractable module because $\mathrm{M}$ is coretractable module . Now, let $\mathrm{K}$ be a proper submodule of $M$. Since $M$ is coretractable module , then there exists a nonzero R-homomorphism $f: M \rightarrow M, f(K)=0$, so $\mathrm{K} \subseteq$ kerf . But $\mathrm{M}$ is purely Rickart module, so kerf pure submodule of $\mathrm{M}$. As $\mathrm{f} \neq 0$ hence kerf $\neq \mathrm{M}$ and hence kerf is a proper pure submodule such that $\mathrm{K} \subseteq \mathrm{W} \subset \mathrm{M}$ (Where $\mathrm{W}=\mathrm{kerf}$ ) .

$(\Leftarrow)$ Let $\mathrm{K}$ be a proper submodule of $\mathrm{M}$. By hypothesis there exists a pure submodule $\mathrm{W}$ of $\mathrm{M}$ such that $\mathrm{K} \subseteq \mathrm{W}$. Since $M$ is P-coretractable, hence $f \in \operatorname{End}_{R}(M)$ such that $f(W)=0, f \neq 0$ implies to $f(K)=0$. Then $M$ is coretractable module .

Recall that, let $M$ be a right $R$-module and $S=\operatorname{End}_{R}(M)$. Then $M$ is said to be dual-purely Rickart (shortly, dual purely Rickart) module if the image in $M$ of any single element of $S$ is pure in $M$. That is for each $\alpha \in S$, Im $\alpha$ is pure submodule in M [14] .

Proposition(1.9): Let $\mathrm{M}$ be a mono-coretractable R-module . Then $\mathrm{M}$ is dual purely Rickart module , if $\mathrm{M}$ is purely Rickart module.

Proof : Let $\mathrm{f} \in \operatorname{End}_{\mathrm{R}}(\mathrm{M})$. Since $\mathrm{M}$ is mono-coretractable module , then there exists $\mathrm{g} \in \mathrm{End} \mathrm{R}_{\mathrm{R}}(\mathrm{M})$ such that $\mathrm{Imf}=\mathrm{kerg}$. As $\mathrm{M}$ is purely Rickart module, if kerg is pure submodule of $\mathbf{M}$. Thus Imf is pure submodule of $\mathbf{M}$ and so $\mathbf{M}$ is dual purely Rickart module.

Recall that an R-module $\mathrm{M}$ is called finitely presented if any finite generated submodule of $\mathrm{M}$ is direct summand [6] . Proposition(1.10): Let M be a Noetherian finitely presented R-module. Then M is a P-coretractable module .

Proof : Let $\mathrm{N}$ be a proper pure submodule of M. Since $\mathrm{M}$ is Noetherian module. Then $\mathrm{N}$ is finitely generated . As $\mathrm{M}$ is finitely presented, so $\mathrm{N}$ is direct summand submodule by [6,Lam.Exc.32,P.163]. Then $\mathrm{N} \oplus \mathrm{W}=\mathrm{M}$ for some a submodule $\mathrm{W}$ of $\mathrm{M}$, so $\mathrm{M} / \mathrm{N} \cong \mathrm{W}$. Then $\mathrm{M}$ is $\mathrm{P}$-coretractable .

Proposition(1.11):Let M be a Noetherian projective R-module . Then M is a P-coretractable module.

Proof : Let $\mathrm{N}$ be a proper pure submodule of M. Since M is Noetherian module, N is finitely generated . Hence by [15], $\mathrm{N}$ is a direct summand, then $\mathrm{M}=\mathrm{N} \oplus \mathrm{W}$ for some a submodule $\mathrm{W}$ of $\mathrm{M}$, then there exists an isomorphism $\mathrm{f}: \mathrm{M} / \mathrm{N} \rightarrow \mathrm{W}$ and let $\mathrm{i}: \mathrm{W} \rightarrow \mathrm{M}$ be the inclusion map, therefore $\mathrm{i} \circ \mathrm{f}: \mathrm{M} / \mathrm{N} \rightarrow \mathrm{M}, \mathrm{i} \circ \mathrm{f} \neq 0$. Thus $\mathrm{M}$ is $\mathrm{P}$-coretractable module .

Now, we can present an example of P-coretractable but not coretractable .

Example (1.12): Consider $\mathrm{M}=\mathrm{Z} \oplus \mathrm{Z}$ as $\mathrm{Z}$-module , $\mathrm{M}$ is Noetherian and projective and so $\mathrm{M}$ is $\mathrm{P}$-coretractable by Proposition(1.11), but $\mathrm{M}$ is not coretractable module .

The following result follows by Proposition(1.11), Since $\mathrm{R}$ is projective

Corollary (1.13): Let $\mathrm{R}$ be a Noetherian ring. Then $\mathrm{R}$ is a P-coretractable ring. The ring of integers $\mathrm{Z}$ is Noetherian, so It is a P-coretractable, but $\mathrm{Z}$ is not coretractable ring. Recall that a submodule $\mathrm{N}$ of an $\mathrm{R}$-module $\mathrm{M}$ is called fully invariant if $f(N)$ is contained in $N$ for every R-endomorphism f of $M$ [16] and a submodule $N$ of an R-module $M$ is called stable if for each $\mathrm{f} \in \operatorname{Hom}(\mathrm{N}, \mathrm{M}), \mathrm{f}(\mathrm{N}) \subseteq \mathrm{N}$ where an R-module $\mathrm{M}$ is called fully stable if every submodule of $\mathrm{M}$ is stable [17] .

Proposition(1.14):Let $\mathrm{N}$ be a direct summand submodule of a P-coretractable R-module $\mathrm{M}$. If $\mathrm{N}$ is fully invariant submodule of $\mathrm{M}$, then $\mathrm{N}$ is $\mathrm{P}$-coretractable.

Proof : Since $\mathrm{N}$ is a direct summand submodule, so there exists a submodule $\mathrm{W}$ of $\mathrm{M}$ such that $\mathrm{N} \oplus \mathrm{W}=\mathrm{M}$. Let $\mathrm{K}$ be a proper pure submodule of $\mathrm{N}$, we have $\mathrm{K} \oplus \mathrm{W}$ is apure submodule in $\mathrm{N} \oplus \mathrm{W}=\mathrm{M}$ ( Since $\mathrm{K}$ is pure in $\mathrm{N}$ and $\mathrm{W}$ is pure in $W$ ). Since $M$ is a P-coretractable module, so there exists $f \in E_{R}(M), f \neq 0, f(K \oplus W)=0$. suppose that $g$ is the restriction map of $\mathrm{f}$ from $\mathrm{N}$ into $\mathrm{M}, \mathrm{g} \neq 0$. Also $\mathrm{N}$ is fully invariant direct summand. Then $\mathrm{N}$ is stable submodule . So $\mathrm{g}(\mathrm{N}) \subseteq \mathrm{N}$. Therefore $\mathrm{g} \in \mathrm{End}_{\mathrm{R}}(\mathrm{N}), \mathrm{g} \neq 0 . \mathrm{g}(\mathrm{K})=\mathrm{f}_{\mathrm{N}}(\mathrm{K})=0$. Thus $\mathrm{N}$ is P-coretractable module .

Corollary(1.15): Let $\mathrm{N}$ be a direct summand submodule of a P-coretractable and duo R-module $\mathrm{M}$, then $\mathrm{N}$ is $\mathrm{P}$ coretractable . where a module $\mathrm{M}$ is duo if every submodule is fully invariant [12]

Proof : It is clear since every submodule if fully invariant in duo module

Recall that an R-module $M$ is called cogenerator if for every nonzero homomorphism $\mathrm{f}: \mathrm{M}_{1} \rightarrow \mathrm{M}_{2}$ where $\mathrm{M}_{1}$ and $\mathrm{M}_{2}$ are R-modules, there exists $\mathrm{g}: \mathrm{M}_{2} \rightarrow \mathrm{M}$ such that $\mathrm{g} \circ \mathrm{f} \neq 0$ [6, P.507] and [3, P.53] .

Proposition(1.16): Let $\mathrm{N}$ be a direct summand of a P-coretractable module $\mathrm{M}$. If $\mathrm{N}$ is cogenerates $\mathrm{M}$. Then $\mathrm{N}$ is $\mathrm{P}$ coretractable module.

Proof: Suppose $\mathrm{N}$ is cogenerates $\mathrm{M}$, so there exists $\mathrm{g} \in \mathrm{Hom}_{\mathrm{R}}(\mathrm{M}, \mathrm{N}), \mathrm{g} \neq 0$. Let $\mathrm{K}$ be a pure submodule of $\mathrm{N}$. Since $\mathrm{N}$ is direct summand of $\mathrm{M}$, then $\mathrm{N} \oplus \mathrm{W}=\mathrm{M}$ for some a submodule $\mathrm{W}$ of $\mathrm{M}$. So $\mathrm{K} \oplus \mathrm{W}$ is pure in $\mathrm{N} \oplus \mathrm{W}=\mathrm{M}$. Then there exists $\mathrm{f} \in \operatorname{End}_{\mathrm{R}}(\mathrm{M}), \mathrm{f} \neq 0, \mathrm{f}(\mathrm{K} \oplus \mathrm{W})=0$. Hence $\mathrm{g} \circ \mathrm{f} \neq 0$, Let $\mathrm{h}$ be a restriction map of $\mathrm{g} \circ \mathrm{f}$ on $\mathrm{N}$, so $\mathrm{h} \in \mathrm{End} \mathrm{R}_{\mathrm{R}}(\mathrm{N})$ and $\mathrm{h}(\mathrm{K})=\mathrm{g}(\mathrm{f}(\mathrm{K}))=0$. Therefore $\mathrm{N}$ is P-coretractable module .

For an R-module M . Recall that a module M has the pure intersection property (briefly PIP ) if the intersection of any two pure submodules is again pure [9] .

Theorem (1.17) : Let $\left\{\mathrm{M}_{\alpha}: \alpha \in \mathrm{I}\right\}$ be a family of P-coretractable R-module if for any $\alpha, \beta \in \mathrm{I}, \mathrm{M}_{\alpha}$ is $\mathrm{M}_{\beta}-$ injective and $\mathrm{M}=\oplus_{\alpha \in I} M_{\alpha}$ has PIP, then $\mathrm{M}$ is P-coretractable . In particular, if $\mathrm{M}$ is quasi-injective P-coretractable and satisfy $\mathrm{PIP}$, then $=\bigoplus_{\alpha \in I} M_{\alpha}$ is P-coretractable for any index I, $\mathrm{M}_{\alpha}=\mathrm{M}$ for all $\alpha \in \mathrm{I}$. 
Proof : Let $K$ be a proper pure submodule of $M$, then there exists $\beta \in I$ such that $M_{\beta} \nsubseteq K$. Since $K$ is pure in $M$ and $M_{\beta}$ is pure in $\mathrm{M}$ and $\mathrm{M}$ satisfies PIP, so $\mathrm{K} \cap \mathrm{M} \beta \subset \mathrm{M}_{\beta}$, and it is a proper pure submodule in $\mathrm{M}_{\beta}$. Therefore there exists a

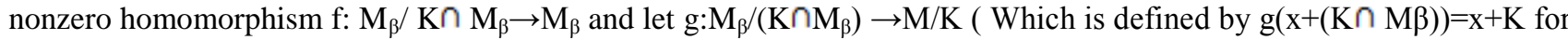
all $\mathrm{x} \in \mathrm{M} \beta \subset \mathrm{M})$, then $\mathrm{g}$ is a monomorphism . As $\mathrm{M}_{\beta}$ is $\mathrm{M}_{\alpha}$-injective for any $\alpha \in \mathrm{I}$ by hypothesis, $\mathrm{M}_{\beta}$ is $\mathrm{M} / \mathrm{K}$-injective by [3, proposition16.13], so there exists $\mathrm{h}: \mathrm{M} / \mathrm{K} \rightarrow \mathrm{M}_{\beta}$ such that $\mathrm{h} \cdot \mathrm{g}=\mathrm{f}$. Hence $0 \neq \mathrm{i} \circ \mathrm{h} \in \mathrm{Hom}_{\mathrm{R}}(\mathrm{M} / \mathrm{K}, \mathrm{M})$, where $\mathrm{i}: \mathrm{M}_{\beta} \rightarrow \mathrm{M}$ is the natural inclusion

Theorem (1.18): Let $\mathrm{M}=\oplus_{\alpha \in I} \mathrm{M}_{\alpha}$ such that $\mathrm{M}_{\alpha}$ be a P-coretractable module $\alpha \in \mathrm{I}$. If every pure submodule in $\mathrm{M}$ is fully invariant, then $\mathrm{M}$ is P-coretractable module .

Proof : Let $\mathrm{N}$ be a proper pure submodule of $\mathrm{M}$. By hypothesis $\mathrm{N}$ is fully invariant, $\mathrm{N}=\oplus_{a \in I}\left(\mathrm{~N}_{\mathrm{N}} \cap \mathrm{M}_{\mathfrak{a}}\right)$. Put $N \cap M_{\alpha}=N_{\alpha}$ for all $\alpha \in I$, since $N \cap N_{\propto} \leq{ }^{\oplus} N$, then $N_{\alpha}$ is pure submodule in $N$, but $N$ is pure in $M$, then $N_{\alpha}$ pure in $\mathrm{M}$. As $\mathrm{N}_{\alpha} \leq \mathrm{M}_{\alpha}$, we get $\mathrm{N}_{\propto}$ is pure in $\mathrm{M}_{\alpha}$. Also since $\mathrm{N}$ is a proper submodule of $\mathrm{M}$, there exists at least one $\propto_{i} \in \mathrm{I}, N_{\alpha_{i}}$ proper submodule of $M_{a_{i}}$. But $M_{a_{i}}$ is P-coretractable, so there exists $f_{a_{i}}: M_{\alpha} / N_{\alpha} \rightarrow M_{\alpha}$ and $f_{\alpha} \neq 0$. As $M / N \cong \bigoplus_{\alpha \in I}\left(M_{\alpha} /\right.$

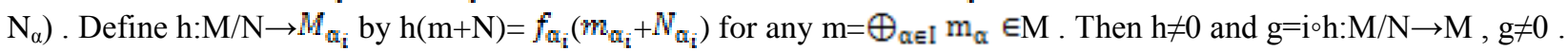

\section{MONO-P-CORETRACTABLE MODULES}

In this section, we introduce the notion of mono-P-coretractable module and study some properties of this class module.

Definition(2.1): An an R-module $\mathrm{M}$ is called mono-P-coretractable if for all a proper pure submodule of $\mathrm{M}$, there exists $\mathrm{f} \in \mathrm{End}_{\mathrm{R}}(\mathrm{M}), \mathrm{f} \neq 0$ and $\mathrm{N}=\mathrm{kerf}$. Equivalently, A module $\mathrm{M}$ is mono-P-coretractable if for each proper pure submodule $\mathrm{N}$ of $\mathrm{M}$, there exists a monomorphism $\mathrm{f}$ from $\mathrm{M} / \mathrm{N}$ into $\mathrm{M}$.

Recall that an R-module $\mathrm{M}$ is called co-epi-retractable if it contains a copy of any of its factor modules [18] . However, for more convenient, we call it mono-coretractable module.

Examples and Remarks (2.2):

(1) Every pure split module is a mono-P- coretractable

(2) Every mono-coretractable module is mono-P-coretractable .

(3) Every pure simple module is mono-P-coretractable .

(4) Every mono-P-coretractable module is P-coretractable .

(5) Every semisimple module is mono-coretractable and hence it is mono-P-coretractable module by part(3) .

(6) Let $\mathrm{M}$ be an $\mathrm{R}$-module. If $\mathrm{M}$ is a quasi-Dedekind mono-P-coretractable, then $\mathrm{M}$ is a pure simple .

Proof : Let $\mathrm{N}$ be a proper pure submodule of $\mathrm{M}$. Since $\mathrm{M}$ is mono-P- coretractable, so there exists $\mathrm{f} \in \mathrm{End} \mathrm{R}_{\mathrm{R}}(\mathrm{M}), \mathrm{f} \neq 0$, $f(N)=0$ and $N=$ kerf, but $M$ is quasi-Dedekind, hence kerf $=0$. Thus $N=0$ and hence $M$ is pure simple module .

Let $\mathrm{M}$ be a right $\mathrm{R}$-module and let $\mathrm{S}=\operatorname{End}_{\mathrm{R}}(\mathrm{M})$. Recall that an R-module $\mathrm{M}$ is called a Rickart module if the right annihilator in $\mathrm{M}$ of any single element of $\mathrm{S}$ is generated by an idempotent of $\mathrm{S}$. Equivalently, $\mathrm{M}$ is called Rickart module if for all $\mathrm{f} \in \mathrm{S}$, kerf $<^{\oplus} \mathrm{M}[19]$.

Proposition(2.3): Let $\mathrm{M}$ be a Rickart R-module . Then $\mathrm{M}$ is a mono-P-coretractable if and only if $\mathrm{M}$ is a pure split .

Proof : $(\Rightarrow)$ Let $N$ be a proper pure submodule of M . Since M is mono-P- coretractable, then there exists $f \in E n d_{R}(M)$, $\mathrm{f} \neq 0$ and $\mathrm{N}=$ kerf , but $\mathrm{M}$ is a Rickart, hence kerf is a direct summand of $\mathrm{M}$ for each $\mathrm{f} \in \mathrm{End}_{\mathrm{R}}(\mathrm{M})$ and so $\mathrm{N}$ is direct summand of $\mathrm{M}$. Thus $\mathrm{M}$ is pure split module .

$(\Leftarrow)$ It follows by Examples and Remarks(2.2 (1)) .

Recall that an R-module $M$ is called a strongly Rickart if and only if kerf $=r_{M}(f)$ is a fully invariant direct summand in $\mathrm{M}$ for all $\mathrm{f} \in \mathrm{End}_{\mathrm{R}}(\mathrm{M})$ [20] .

We introduce the following definition : An R-module M is called P-fully stable if every pure submodule is stable . It is clear that every fully stable is P-fully stable but not conversely .

Proposition(2.4): Let M be a strongly Rickart R-module. Then M is a mono-P-coretractable if and only if a P-fully stable and pure split .

Proof : $(\Rightarrow)$ Let $\mathrm{N}$ be a proper pure submodule of M. Since M is mono-P- coretractable, then there exists $f \in E n d_{R}(M)$, $\mathrm{f} \neq 0$ and $\mathrm{N}=$ kerf , but $\mathrm{M}$ is a strongly Rickart, hence kerf is a stable direct summand of $\mathrm{M}$ for each $\mathrm{f} \in \mathrm{End}_{\mathrm{R}}(\mathrm{M}) \operatorname{and}$ hence $\mathrm{N}$ is a stable direct summand of $\mathrm{M}$. Thus $\mathrm{M}$ is $\mathrm{P}$-fully stable pure split module .

$(\Leftarrow)$ It is clear.

Recall that an R-module $\mathrm{M}$ is called mono-C-coretractable if for each proper closed submodule of $\mathrm{M}$, there exists $f \in \operatorname{End}_{\mathrm{R}}(\mathrm{M}), \mathrm{f} \neq 0$ and $\mathrm{N}=\operatorname{kerf}[8]$.

Proposition(2.5): Let $\mathrm{M}$ be a purely extending. If $\mathrm{M}$ is a mono-P-coretractable module , then $\mathrm{M}$ is a mono-Ccoretractable .

Proof : It is clear since if $\mathrm{N}$ is a proper closed submodule of $\mathrm{M}$, then $\mathrm{N}$ is a pure . As $\mathrm{M}$ is a mono-P-coretractable , so there exists $\mathrm{f} \in \mathrm{End}_{\mathrm{R}}(\mathrm{M}), \mathrm{f} \neq 0, \mathrm{f}(\mathrm{K})=0$ and $\mathrm{K}=$ kerf and hence $\mathrm{M}$ is a mono-C-coretractable . 
Proposition(2.6):Let M be a mono-P-coretractable and P-fully stable module . Then every nonzero pure submodule of $\mathrm{M}$ is also mono-P-coretractable .

Proof : Suppose that $\mathrm{N}$ is a nonzero pure submodule of $\mathrm{M}$. Let $\mathrm{K}$ be a proper pure submodule of $\mathrm{N}$, so $\mathrm{K}$ is pure submodule of $M$. But $M$ is mono-P-coretractable module . Then there exists $f \in \operatorname{End}_{R}(M), f \neq 0, f(K)=0$ and $K=k e r f$, so if $\mathrm{f}(\mathrm{N})=0$, then $\mathrm{N} \subseteq$ kerf $=\mathrm{K}$ so $\mathrm{N}=\mathrm{K}$ which is a contradiction. Thus $\mathrm{f}(\mathrm{N}) \neq 0$. Let $\mathrm{g}$ be a restriction map from $\mathrm{N}$ into $\mathrm{M}$. Since $M$ is P-fully stable, so $g(N) \subseteq N$. Hence $g \in \operatorname{End}_{R}(N)$ and $g \neq 0$ since $g(N)=f(N) \neq 0$. Hence $g(K)=f(K)=0$. Thus $\mathrm{K} \subseteq$ kerg $\subseteq$ kerf $=\mathrm{K}$. Then $\mathrm{K}=\mathrm{kerg}$.

\section{STRONGLY-P-CORETRACTABLE MODULES}

In this section, we define a new concept concerned directly with pure submodule called strongly P-coretractable module as one of generalization the concept strongly coretractable module see [17], also we introduce some properties and related with this concept .

Definition(3.1): An R-module is called strongly P-coretractable module if for each proper pure submodule K of M , there exists a nonzero homomorphism $\mathrm{f} \in \mathrm{Hom}(\mathrm{M} / \mathrm{K}, \mathrm{M})$ and $\mathrm{f}(\mathrm{M} / \mathrm{K})+\mathrm{K}=\mathrm{M}$. Equivalently, $\mathrm{M}$ is strongly P-coretractable $R$-module if for each proper pure submodule $K$ of $M$, there exists $g \in \operatorname{End}_{R}(M), g(M / K)+K=M, g \neq 0$ and $g(K)=0$. A ring $\mathrm{R}$ is called strongly $\mathrm{P}$-coretractable if $\mathrm{R}$ is strongly $\mathrm{P}$-coretractable $\mathrm{R}$-module .

\section{Examples and Remarks(3.2):}

(1) Every strongly coretractable is a strongly P-coretractable module but the converse is not true in general, for example the $\mathrm{Z}$-module $\mathrm{Z}_{4}$ is strongly $\mathrm{P}$-coretractable , but it is not strongly coretractable, where an $\mathrm{R}$-module $\mathrm{M}$ is called strongly coretractable module if for each proper submodule $\mathrm{N}$ of $\mathrm{M}$, there exists a nonzero $\mathrm{R}$ homomorphism $\mathrm{f}: \mathrm{M} / \mathrm{N} \rightarrow \mathrm{M}$ such that $\mathrm{Imf}+\mathrm{N}=\mathrm{M}[2],[8]$.

(2) Every semisimple module is a strongly coretractable and hence strongly P-coretractable .

(3) Every pure simple R-module is a strongly P-coretractable module .

(4) Every pure split module is a strongly P-coretractable module

(5) Every strongly P-coretractable module is a P-coretractable .

Proposition(3.3): Let $\mathrm{M} \cong \mathrm{M}^{\prime}$, where $\mathrm{M}$ is a strongly $\mathrm{P}$-coretractable R-module . Then $\mathrm{M}^{\prime}$ is a strongly $\mathrm{P}$-coretractable R-module.

Proof : Since $M \cong M^{\prime}$, so there exists $\mathrm{f}: \mathrm{M} \rightarrow \mathrm{M}^{\prime}$ be $\mathrm{R}$-isomorphism . Let $\mathrm{W}$ be a proper pure submodule of $\mathrm{M}^{\prime}$. Then $\mathrm{N}=\mathrm{f}^{-1}(\mathrm{~W})$ is proper pure submodule of $\mathrm{M}$. Since $\mathrm{M}$ is strongly $\mathrm{P}$-coretractable module, so there exists a nonzero $\mathrm{R}$ homomorphism $\mathrm{h}: \mathrm{M} / \mathrm{N} \rightarrow \mathrm{M}$ such that $\mathrm{h}(\mathrm{M} / \mathrm{N})+\mathrm{N}=\mathrm{M}$.

Define $\mathrm{g}: \mathrm{M}^{\prime} / \mathrm{W} \rightarrow \mathrm{M}^{\prime}, \mathrm{g}(\mathrm{f}(\mathrm{m})+\mathrm{f}(\mathrm{N}))=\mathrm{f}\left(\mathrm{m}_{1}\right)$ where $\mathrm{h}(\mathrm{m}+\mathrm{N})=\mathrm{m}_{1} \in \mathrm{M}$. To prove $\mathrm{g}$ is well-defined, suppose that $f(m)+f(N)=f(x)+f(N)$ where $m, x \in M$. Then $f(m)-f(x) \in f(N)$, so $f(m-x) \in f(N)$ and so $m-x \in N$. Then $m+N=x+N$. Therefore $h(m+N)=m_{1}=m_{2}=h(x+N)$ (Since $h$ is well-defined ) which implies $g(f(m)+f(N))=f\left(m_{1}\right)=f\left(m_{2}\right)=g(f(x)+f(N)$ ) ( Since $\mathrm{f}$ is well-defined ). Therefore $\mathrm{g}$ is well-defined, also $\mathrm{g}$ is an R-homomorphism .

To prove $g\left(M^{\prime} / W\right)+W=M^{\prime}=f(M)$. Let $m^{\prime} \in M^{\prime}$, then $m^{\prime}=f(m)$ for some $m \in M$. But $m=h\left(m_{1}+N\right)+n_{1}$ for some $\mathrm{m}_{1} \in \mathrm{M}$ and $\mathrm{n}_{1} \in \mathrm{N}$. Let $\mathrm{h}\left(\mathrm{m}_{1}+\mathrm{N}\right)=\mathrm{m}_{2}$, so $\mathrm{m}=\mathrm{m}_{2}+\mathrm{n}_{1}$. But $\mathrm{g}(\mathrm{f}(\mathrm{m})+\mathrm{f}(\mathrm{N}))+\mathrm{f}\left(\mathrm{n}_{1}\right)=\mathrm{f}\left(\mathrm{m}_{2}\right)+\mathrm{f}\left(\mathrm{n}_{1}\right)=\mathrm{f}\left(\mathrm{m}_{2}+\mathrm{n}_{1}\right)=\mathrm{f}(\mathrm{m})=\mathrm{m}^{\prime}$. Therefore $\mathrm{M}^{\prime}=\mathrm{Img}+\mathrm{W}$, we get $\mathrm{M}^{\prime}$ is a strongly P-coretractable R-module .

Proposition(3.4): Let M be a strongly P-coretractable R-module and $\mathrm{N}$ be a proper pure submodule of $\mathrm{M}$, then $\mathrm{M} / \mathrm{N}$ is a strongly P-coretractable module .

Proof : Let W/N be a proper pure submodule of $\mathrm{M} / \mathrm{N}$. Since $\mathrm{N}$ is pure submodule of $\mathrm{M}$, so $\mathrm{W}$ is pure submodule of $\mathrm{M}$. But $\mathrm{M}$ is strongly $\mathrm{P}$-coretractable module Then there exists a nonzero R-homomorphism $\mathrm{g}: \mathrm{M} / \mathrm{W} \rightarrow \mathrm{M}$ such that $\operatorname{Img}+\mathrm{W}=\mathrm{M}$. But $(\mathrm{M} / \mathrm{N}) /(\mathrm{W} / \mathrm{N}) \cong \mathrm{M} / \mathrm{W}$. Set $\mathrm{f}=\pi^{\circ} \mathrm{g}$ where $\pi$ is the natural epimorphism from M into M/W . Then $\mathrm{f}\left(\frac{M}{W}\right)+$ $\frac{W}{W}=\pi\left(\mathrm{g}\left(\frac{M}{W}\right)\right)+\frac{W}{W}=\frac{g\left(\frac{M}{W}\right)+N}{N}+\frac{W}{W}=\frac{g\left(\frac{M}{W}\right)+N+W}{N}=\frac{M+N}{N}=\frac{M}{N}$, and $\mathrm{f} \neq 0$ ( because if $\mathrm{f}$ is a zero mapping, then $\mathrm{M} / \mathrm{N}=\mathrm{W} / \mathrm{N}$ which is a contradiction ), we can get $\mathrm{M} / \mathrm{N}$ is also strongly $\mathrm{P}$-coretractable .

Corollary(3.5): Let $\mathrm{M}$ be an R-module . If $\mathrm{M}$ is a strongly P-coretractable module. Then any direct summand submodule of $\mathrm{M}$ is a strongly $\mathrm{P}$-coretractable module .

Proof : Since N is direct summand submodule of M , so there exists $\mathrm{W}$ is pure submodule of $\mathrm{M}$ such that $\mathrm{N} \oplus \mathrm{W}=\mathrm{M}$. Thus $\mathrm{M} / \mathrm{W}$ is strongly P-coretractable module by Proposition(3.4) . But $\mathrm{M} / \mathrm{W} \cong \mathrm{N}$ so that $\mathrm{N}$ is also strongly $\mathrm{P}$ coretractable module by Proposition(3.3)

Proposition(3.6): Let $\mathrm{M}=\mathrm{M}_{1} \oplus \mathrm{M}_{2}$, where $\mathrm{M}$ is duo module (or distributive or $\operatorname{ann} \mathrm{M}_{1}+\operatorname{ann} \mathrm{M}_{2}=\mathrm{R}$ ). Then $\mathrm{M}$ is a strongly P-coretractable module if and only if $\mathrm{M}_{1}$ and $\mathrm{M}_{2}$ are strongly P-coretractable modules .

Proof : $(\Rightarrow)$ It follows directly by Corollary(3.5).

$(\Leftarrow)$ Let $\mathrm{N}$ be a proper pure submodule of $\mathrm{M}$. Since $\mathrm{M}$ is duo (or distributive or annM $\mathrm{M}_{1}+\operatorname{annM}_{2}=\mathrm{R}$ ), then $\mathrm{N}=\left({\mathrm{N} \cap \mathrm{M}_{1}}_{1}\right)$ $\oplus\left(\mathrm{N} \cap M_{2}\right)$. Thus $\mathrm{N}=\mathrm{N}_{1} \oplus \mathrm{N}_{2}$ for some $\mathrm{N}_{1} \leq \mathrm{M}_{1}$ and $\mathrm{N}_{2} \leq \mathrm{M}_{2}$. Thus each of $\mathrm{N}_{1}$ and $\mathrm{N}_{2}$ are pure submodules in $\mathrm{M}_{2}$ and $\mathrm{M}_{2}$ 
respectively. Thus By the same argument proof of Theorem(2.7) in [2], we can get $\mathrm{M}$ is a strongly P-coretractable module .

Compare the following Propositions with Proposition(1.3), Proposition(1.5) and Proposition(1.8) respectively .

Proposition(3.7): Let M be a purely extending R-module, if $\mathrm{M}$ is strongly P-coretractable module , then $\mathrm{M}$ is strongly C-coretractable .

Proposition(3.8): Let $\mathrm{M}$ be an F-regular R-module, then $\mathrm{M}$ is strongly coretractable module if and only if $\mathrm{M}$ is strongly P-coretractable module .

Proposition(3.9): Let M be a purely Rickart R-module. Then M is strongly coretractable module if and only if for all proper submodule $\mathrm{K}$ of $\mathrm{M}$, there exists a pure submodule $\mathrm{W}$ of $\mathrm{M}$ such that $\mathrm{K} \subseteq \mathrm{W}$ and $\mathrm{M}$ is strongly $\mathrm{P}$-coretractable .

Proposition(3.10): Let $\mathrm{M}$ be a Noetherian finitely presented R-module. Then $\mathrm{M}$ is a strongly P-coretractable module .

Proof : Let $\mathrm{N}$ be a proper pure submodule of M. Since M is Noetherian module. Then $\mathrm{N}$ is finitely generated . As M is finitely presented, so $\mathrm{N}$ is direct summand submodule by [6,Lam.Exc.32,P.163]. Then $\mathrm{N} \oplus \mathrm{W}=\mathrm{M}$ for some a submodule $\mathrm{W}$ of $\mathrm{M}$, so $\mathrm{M} / \mathrm{N} \cong \mathrm{W}$. Consider $(\mathrm{i} \circ \mathrm{f})(\mathrm{M} / \mathrm{N})+\mathrm{N}=\mathrm{W} \oplus \mathrm{N}=\mathrm{M}$. Then $\mathrm{M}$ is strongly P-coretractable module .

By a similar proof Corollary(1.6), Proposition(1.14) and Theorem(1.18), we can get the following result .

Corollary(3.11):If $\mathrm{M}$ is a purely lifting V-module. Then $\mathrm{M}$ is a strongly P-coretractable if and only if $\mathrm{M}$ is a strongly coretractable module .

Proposition(3.12): Let $\mathrm{M}$ be a Noetherian projective R-module. Then $\mathrm{M}$ is a strongly P-coretractable module .

Theorem (3.13): Let $\left\{\mathrm{M}_{\alpha}: \alpha \in \mathrm{I}\right\}$ be a family of strongly P-coretractable R-module if for any $\alpha, \beta \in \mathrm{I}_{,} \mathrm{M}_{\alpha}$ is $\mathrm{M}_{\beta}$ injective and $\mathrm{M}=\oplus_{\alpha \in I} M_{\alpha}$ has PIP, then $\mathrm{M}$ is a strongly P-coretractable . In particular, if $\mathrm{M}$ is quasi-injective $\mathrm{P}$ coretractable and satisfy PIP, then M is P-coretractable for any index I .

Proposition(3.14): Let M be a quasi-Dedekind R-module, then the following statements are equivalent :

(1) $\mathrm{M}$ is a strongly $\mathrm{P}$-coretractable ;

(2) $\mathrm{M}$ is a P-coretractable ;

(3) $\quad \mathrm{M}$ is a pure simple ;

(4) $\mathrm{M}$ is a mono-P-coretractable .

Proof : $(1) \Rightarrow(2)$ It is clear by Examples and Remarks(3.2(5)).

$(2) \Rightarrow(3)$ It follows by Proposition(1.7) since $M$ is a quasi-Dedekind module.

$(3) \Rightarrow(4)$ It follows by Examples and $\operatorname{Remarks}(2.2(3))$.

$(4) \Rightarrow(1)$ Let $\mathrm{M}$ be a mono-P-coretractable . It is clear that $\mathrm{M}$ is P-coretractable. As $\mathrm{M}$ is quasi-Dedekind , so again $\mathrm{M}$ is a pure simple by Proposition(1.7) and hence M is strongly P-coretractable by Examples and Remarks(3.2(3)) .

\section{REFERENCES}

[1] Amini B. , Ershad M. , and Sharif H. , "Coretractable Modules”, J. Aust. Math. Soc, vol. 86, no. 3, pp. 289-304, 2009.

[2] Hadi I. , Al-aeashi S. ," Strongly Coretractable Modules and Related Concepts", Journal Of Advances In Mathematics, Vol. 12, No. 12, Pp.6881-6888 . 2016.

[3] Fuller K.R., "Rings And Categories Of Modules", Springer, Newyork, 1982.

[4] Fieldhous D.J., "Purity And Flatness", Ph.D. Thesis, McGill University, 1967.

[5] Azumaya G. and Faccini A., "Rings of pure global dimension zero and Mittag-leffler modules", J. pure Appl. Algebra, 62 1989, $109-122$

[6] Lam T. Y., " Lectures on Modules and Rings ", (Springer, New York, 1999.

[7] Yaseen S. M., "Coquasi-Dedekind Modules", Ph.D. Thesis, University Of Baghdad, Baghdad,Iraq, 2003.

[8] I.M.Ali Hadi and Sh. N. Al-aeashi," C-Coretractable Modules ", International Journal Of Pure and Applied Mathematics , to appear.

[9] Al-Zubaidey Z. ,"On Purely Extending Modules", Msc.Thesis , Univ. of Baghdad , Iraq, 2005.

[10] Yaseen S. M.,"On F-regular Modules",M. sc. Thesis, University of Baghdad, Iraq,1993.

[11] Garib N.H.,"Some Generalizations Of Lifting Modules"Ph.D. Thesis, University Of Sulaimani ,Iraq, 2007.

[12] Dangh N.V., Huynh D.V., Smith P.F. and Wisbauer R.,"Extending Modules", Pitman Reseach Notes In Mathematics Series 313, Longman, New York 1994 .

[13] Mijbass A.S.,"Quasi-Dedekind Modules ", Ph.D. Thesis, University of Baghdad , Iraq, 1997.

[14] Al-Saadi S.A., Ibrahiem T.A.," Dual Purely Rickart Modules ", Journal of Mathematics, Vol.11, PP 12-19, 2015.

[15] Oneto A.V.,"Purity And Direct Summand", Divulaciciones Matem , Aticas Vol. 4 No. 1/2 - 59-54,1996.

[16] Ozcan A. C., A. Harmanci and P. F. Smith " Duo Modules ", Glasgow Math. J. 48 (2006) 533-545.

[17] Hadi I. , Al-aeashi S. ," Y-coretractable and Strongly Y-Coretractable Modules ", Asian Journal of Applied Sciences, Vol. 5, No. 2 , Pp.427-433 . 2017.

[18] Ghorbani A., "Co-Epi-Retractable Modules And Co-Pri-Rings", Comm. Algebra 38, No. 10, 3589-3596,(2010).

[19] Lee G. "Theory Of Rickart Modules", Ph.D. Thesis , the Ohio State University, Ohio State, U.S.A(2010).

[20] Al-Saadi S.A., Ibrahiem T.A.," Strongly Rickart Rings ", Mathematical Theory and Modeling, Vol.4, No.8,95-105, 2014 